Superalloys 2012: $12^{\text {th }}$ International Symposium on Superalloys

\title{
FATIGUE FAILURE MODES OF THE GRAIN SIZE TRANSITION ZONE IN A DUAL MICROSTRUCTURE DISK
}

\author{
Tim P. Gabb ${ }^{1}$, Pete T. Kantzos², Bonny Palsa ${ }^{1}$, Jack Telesman ${ }^{1}$, John Gayda ${ }^{1}$, Chantal K. Sudbrack ${ }^{1}$ \\ ${ }^{1}$ NASA Glenn Research Center; 21000 Brookpark Rd.; Cleveland, OH 44135 \\ ${ }^{2}$ Honeywell Engine Systems, 111 South 34th St., Phoenix, AZ 85034
}

Keywords: dual microstructure, transition zone, fatigue

\begin{abstract}
Mechanical property requirements vary with location in nickelbased superalloy disks. In order to maximize the associated mechanical properties, heat treatment methods have been developed for producing tailored grain microstructures. In this study, fatigue failure modes of a grain size transition zone in a dual microstructure disk were evaluated. A specialized heat treatment method was applied to produce varying grain microstructure in the bore to rim portions of a powder metallurgy processed nickel-based superalloy disk. The transition in grain size was concentrated in a zone of the disk web, between the bore and rim. Specimens were extracted parallel and transversely across this transition zone, and multiple fatigue tests were performed at $427{ }^{\circ} \mathrm{C}$ and $704{ }^{\circ} \mathrm{C}$. Grain size distributions were characterized in the specimens, and related to operative failure initiation modes. Mean fatigue life decreased with increasing maximum grain size, going out through the transition zone. The scatter in limited tests of replicates was comparable for failures of uniform gage specimens in all transition zone locations examined.
\end{abstract}

\section{Introduction}

In $\gamma^{\prime}$ strengthened superalloys, solution heat treatments at temperatures sufficient to dissolve all existing $\gamma^{\prime}$ precipitates allow enhanced grain growth [1], as the precipitates no longer constrain grain boundaries. This behavior is especially evident in powder metallurgy disk superalloys [2], where application of such a heat treatment after extrusion and forging can produce quite uniform grain sizes $[3,4]$. Disks heated to $20{ }^{\circ} \mathrm{C}-40{ }^{\circ} \mathrm{C}$ below the $\gamma^{\prime}$ solvus in "subsolvus" solution heat treatments retain $10 \%$ $20 \%$ of coarse "primary" $\gamma^{\prime}$ particles, which constrain grain growth to give uniform microstructures with grains near $5 \mu \mathrm{m}-10$ $\mu \mathrm{m}$ in diameter. This fine grain size can give high strength and fatigue resistance at temperatures up to $550{ }^{\circ} \mathrm{C}$, as often required in disk bore and web regions. However, disks heated above the $\gamma^{\prime}$ solvus in "supersolvus" solution heat treatments lose constraining coarse "primary" $\gamma^{\prime}$ particles, allowing grains to grow near $30 \mu \mathrm{m}$ - $70 \mu \mathrm{m}$ in diameter. Such coarse grains can give lower strength and cyclic fatigue resistance, but can improve time-dependent properties such as creep and dwell fatigue cracking at application temperatures of $600{ }^{\circ} \mathrm{C}-700{ }^{\circ} \mathrm{C}$, often required in disk rim regions for high performance gas turbine engines [5-8].

The ability to achieve a fine grain size in the bore and web of a disk, and coarse grain size in the rim of a disk, is therefore a promising approach to help optimize the disk design. Based on these perceived benefits, specialized heat treatment methods have been developed for producing tailored grain microstructures in the bore and rim portions of nickel-based superalloy disks [5-8]. These methods can limit the bore to subsolvus temperatures producing fine grain sizes near $5 \mu \mathrm{m}-10 \mu \mathrm{m}$ in diameter, while allowing the rim to reach supersolvus temperatures to produce grain sizes of $30 \mu \mathrm{m}-80 \mu \mathrm{m}$ in diameter. This allows disk grain microstructure to be varied in accordance with the property requirements of disk bore and rim locations.

In order to help validate the use of such processes, it is necessary to verify the integrity of the transition zone by determining its fatigue resistance. The transition zone of these disks has a microstructure with variable grain size as a function of location. In coarse grain PM disk superalloys, fatigue failures can often initiate at grains which fail in a crystallographic manner due to concentrated slip [9, 10]. These failing grains often appear to be relatively large with respect to the mean grain size for a given microstructure. Since grain size varies within the transition zone, it is therefore important to determine the fatigue resistance and fatigue failure modes of the transition zone.

The objective of this study was to evaluate the low cycle fatigue resistance of the grain size transition zone in a dual microstructure disk. Specimens were extracted from the transition zone in the circumferential and radial directions. Grain size distributions were determined for each specimen location. Fatigue tests were performed at $427{ }^{\circ} \mathrm{C}$ and $704{ }^{\circ} \mathrm{C}$ to assess comparative fatigue lives and failure modes.

\section{Materials and Methods}

Powder metallurgy superalloy LSHR having the composition in wt. \% of $3.46 \mathrm{Al}, 0.028 \mathrm{~B}, 0.029 \mathrm{C}, 20.7 \mathrm{Co}, 12.52 \mathrm{Cr}, 0.07 \mathrm{Fe}$, 2.73Mo, $1.45 \mathrm{Nb}, 1.6 \mathrm{Ta}$, 3.50Ti, 4.33W, 0.049Zr, bal. Ni and trace impurities was produced using argon atomization by PCC Special Metals Corp. and passed through screens of -270 mesh to give powder particle diameters of no more than about $55 \mu \mathrm{m}$. The powder was then sealed in a stainless steel container, hot compacted, and extruded at a reduction ratio of $6: 1$ by PCC Wyman-Gordon Forgings. Segments of the extrusion billet were machined to cylinders approximately $15 \mathrm{~cm}$ diameter and $20 \mathrm{~cm}$ long, then isothermally forged into flat disks approximately $31 \mathrm{~cm}$ diameter and $6 \mathrm{~cm}$ thick. A contoured disk was then machined with an outer diameter of $30 \mathrm{~cm}$, maximum bore thickness of 5 $\mathrm{cm}$, and rim thickness of $3.8 \mathrm{~cm}$ [7]. The disks were heat treated by Ladish Company, Inc. They were first conventionally subsolvus solution heat treated at $1135{ }^{\circ} \mathrm{C}$ for $2 \mathrm{~h}$ then air cooled, to give a uniform fine grain microstructure of $5 \mu \mathrm{m}-10 \mu \mathrm{m}$ in diameter. The dual microstructure heat treatment (DMHT) 
method then employed had heat sinks to encourage a temporary temperature gradient between a disk's bore and rim regions, with the bore at lower temperature than the rim, Fig. 1. When combined with finite element modeling and positioning of thermocouples at key locations, this allowed the bore to remain at subsolvus temperatures producing grains near $10 \mu \mathrm{m}$ in diameter, while the rim reached supersolvus temperatures resulting in grains near $50 \mu \mathrm{m}$ in diameter. The disk was then given an aging heat treatment of $815^{\circ} \mathrm{C} / 8 \mathrm{~h}$.

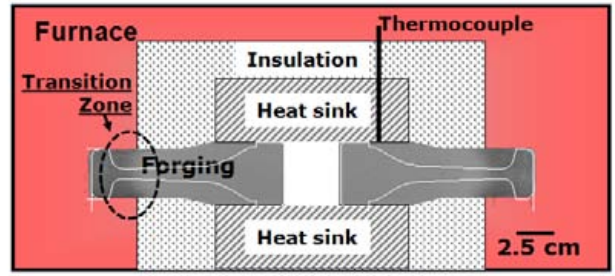

Fig. 1. Dual microstructure heat treatment setup.

Specimen blanks were extracted as shown in Fig. 2. Using rotational symmetry, they were located in three different tangential-oriented rings parallel to the transition zone of inner, mid, and outer radius, and in radial spokes perpendicular to the transition zone. Machining and testing of low cycle fatigue specimens, having a uniform gage diameter of $6.35 \mathrm{~mm}$ across a gage length of $19 \mathrm{~mm}$, was performed by Mar-Test, Inc. Machining of notched specimens having a gage diameter of 9 $\mathrm{mm}$, notch diameter of $6.35 \mathrm{~mm}$, notch radius of $0.92 \mathrm{~mm}$, and elastic stress concentration factor $\left(\mathrm{K}_{\mathrm{t}}\right)$ of 2.0, was performed by Metcut Research Associates. Specimens were machined using a low stress grinding procedure, with the gage sections and notches finally polished to $0.2 \mu \mathrm{m}$ rms finish with all polishing performed parallel to the loading direction. Uniform gage specimens were tested using uniaxial closed-loop servo-hydraulic testing machines with axial extensometers and induction heating. Notched specimens were also tested in such machines, but heated using a resistance heating furnace. Low cycle fatigue tests were performed at $427^{\circ} \mathrm{C}$ and $704^{\circ} \mathrm{C}$.

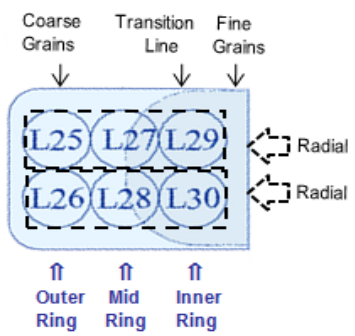

Fig. 2. Specimen locations in transition zone.

The first three of six uniform gage fatigue tests for each location were performed according to ASTM E606, with strain initially controlled to fixed limits. A triangular waveform was employed for the first $6 \mathrm{~h}$ of cycling, varying strain at a frequency of 0.33 $\mathrm{Hz}$ over a total strain range of $0.6 \%$ at a minimum / maximum strain ratio $\left(\mathrm{R}_{\varepsilon}\right)$ of 0 . After $6 \mathrm{~h}$ of testing in this manner, surviving specimens were interrupted and then cycled using a triangular load-controlled waveform at a faster frequency of $10 \mathrm{~Hz}$ until failure, maintaining the stresses stabilized before interruption. The average stabilized maximum and minimum stresses generated in strain control for each specimen location and test temperature defined constant maximum and minimum stress limits for running the other three specimens of the group using a waveform controlling load, according to ASTM E466. A triangular waveform having a frequency of $10 \mathrm{~Hz}$ was employed here. Notched gage specimens were initially tested using a triangular waveform to vary stress, with a maximum stress of $793 \mathrm{MPa}$ and minimum / maximum stress ratio $R_{\sigma}$ of 0.05 . This cyclic test was performed at a frequency of $0.33 \mathrm{~Hz}$ for $6 \mathrm{~h}$, and then continued at $5 \mathrm{~Hz}$ until failure. Later dwell tests were performed with cycles which first applied stress at a frequency of $0.5 \mathrm{~Hz}$, then imposed a dwell of $90 \mathrm{~s}$ at minimum stress.

Fracture surfaces of all specimens were evaluated by scanning electron microscopy to determine failure initiation sites. Grain sizes were determined on metallographically prepared sections. Linear intercept grain size distributions were determined from gage sections of representative test specimens according to ASTM E112 linear intercept procedures using circular grid overlays, grain area distributions were determined using image thresholding, and As-Large-As (ALA) grain sizes were determined according to ASTM E930. Grain size distributions and texture were also assessed using Electron Back Scatter Diffraction (EBSD), in a field emission scanning electron microscope equipped with a backscatter detector and EDAX ${ }^{\circledR}$ TSL electron backscatter diffraction analysis software.

Statistical analyses of variance were performed using JMP@ software, with significance assessed at a probability $p=0.05$, representing $95 \%$ confidence.

\section{Results and Discussion}

Material and Microstructures

Typical grain microstructures are shown in optical images from etched metallographic sections of LCF specimen sections, Fig. 3. Inner, mid, and outer ring specimens had increasing mean intercept grain diameters of $5.8 \mu \mathrm{m}, 38 \mu \mathrm{m}$, and $55 \mu \mathrm{m}$, respectively, and had corresponding increasing ALA grain diameters of about $22 \mu \mathrm{m}, 410 \mu \mathrm{m}$, and $413 \mu \mathrm{m}$, respectively. Because these disks were machined from flat pancake forgings of relatively uniform forging strains, no consistent changes in nonmetallic inclusion content or morphology were observed across the fatigue tested locations.

The grain size transition zone was abrupt in this disk, and was usually captured within the gage cross sections of specimens at the mid location. Within this mid location, a bimodal grain size distribution mixing large and small grains was observed. Inner ring specimens also had coarse, undissolved "primary" $\gamma^{\prime}$ particles widely spaced along grain boundaries and sometimes scattered within grains, Fig. 3. As shown in Fig. 2, the most abrupt region of transition in grain size was located parallel to the loading axis in the gage sections of mid ring specimens. However, this region of grain transition was located normal to the loading axis near the middle of the gage sections in radial specimens. This enabled fatigue loading of the grain size transition plane in the parallel and transverse directions, respectively. 


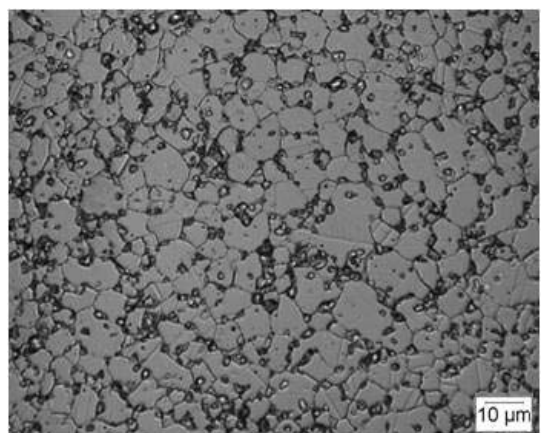

a.

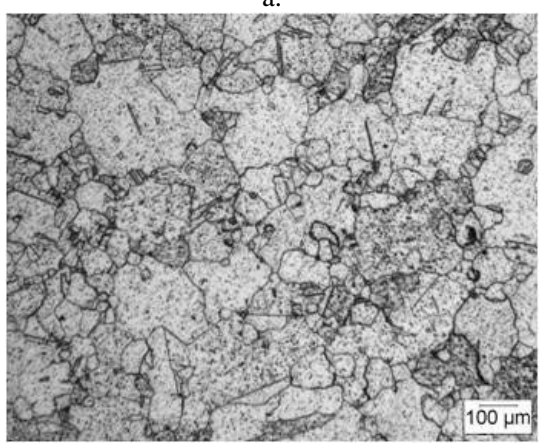

b.

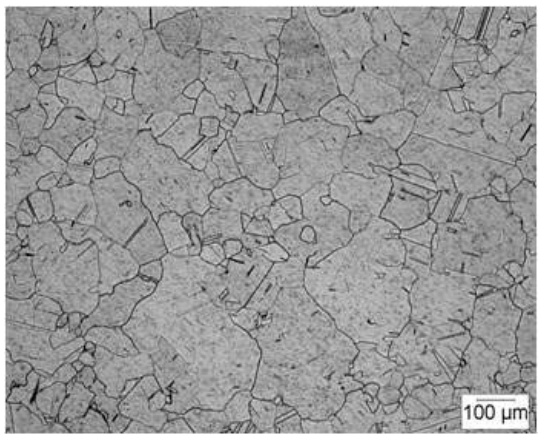

c.

Fig. 3. Grain microstructures for a. inner, b. mid, and c. outer specimen locations.

Low Cycle Fatigue Response

The monotonic and fatigue properties of these DMHT disks were previously compared for bore and rim locations [7]. This discussion will therefore remain focused on the fatigue properties of the grain size transition zone. Fatigue life is compared for the different specimen locations within the transition zone in the cumulative probability plots of Fig. 4. Fatigue lives from specimens of a conventional supersolvus heat treated disk are also included here, which will be considered in a later section. The mean fatigue lives could be compared assuming a log normal distribution, as is evident by the linear fit of the data shown in a plot with a logarithmic life cycle axis. No difference was consistently observed between strain-controlled and loadcontrolled test lives [11]. The resulting lives were therefore grouped together in all analyses.
As shown in Fig 4, for tests conducted at both $427^{\circ} \mathrm{C}$ and $704{ }^{\circ} \mathrm{C}$, the inner location specimens had significantly higher mean fatigue lives than mid, outer, and radial specimens at both test temperatures. Inner specimens had over $10 \mathrm{x}$ higher mean lives than mid, outer, and radial specimens at $427{ }^{\circ} \mathrm{C}$, and over $50 \mathrm{x}$ higher mean lives at $704{ }^{\circ} \mathrm{C}$. Mid, radial, and then outer specimens ranked in order of decreasing mean fatigue lives at both test temperatures, however the differences in lives between these three locations were relatively modest. Outer samples had lower mean lives than those of mid and radial specimens at a 95 $\%$ significance level for tests at $427^{\circ} \mathrm{C}$, but at lower significance levels in tests at $704{ }^{\circ} \mathrm{C}$. Modest scatter in life was observed for each specimen location.
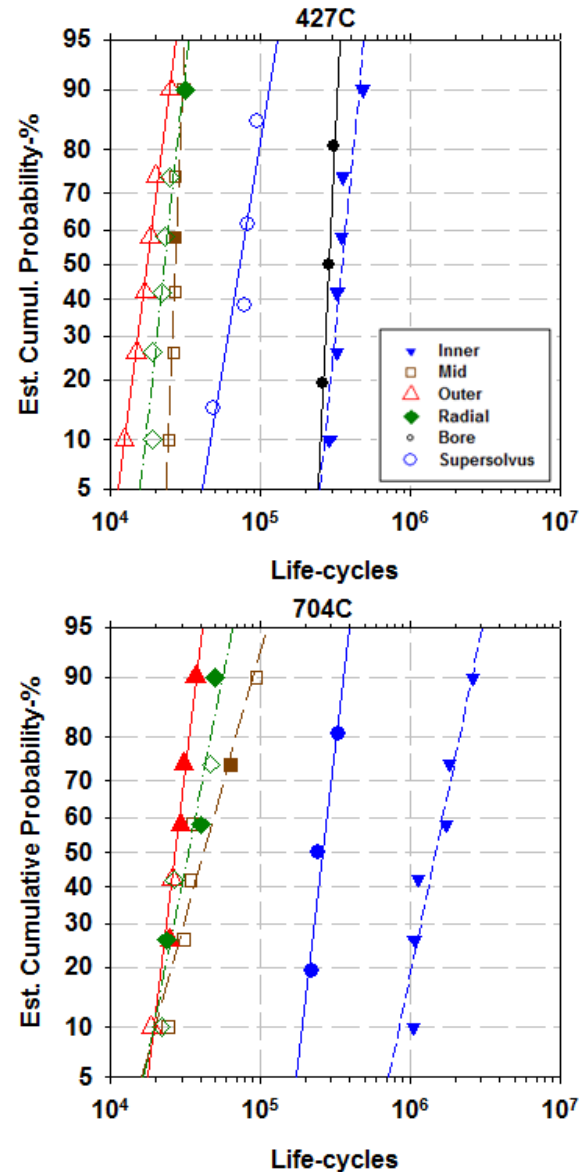

Fig. 4. Comparison of fatigue lives for all uniform gage specimens. Filled symbols indicate internally initiated failures, open symbols indicate surface and near-surface initiated failures.

Mean fatigue lives were significantly lower at $427^{\circ} \mathrm{C}$ than at 704 ${ }^{\circ} \mathrm{C}$ for all transition zone specimen locations. This has also been observed in other studies [10,12] of PM disk superalloys, and will be considered with respect to the failure modes and locations, and the stresses generated at each temperature. Several additional specimens extracted and tested from the bore of the disk had lives comparable to the inner ring specimens at $427^{\circ} \mathrm{C}$ [7], indicating fatigue life was likely comparable over this inward region of the 
disk. The bore specimens of this DMHT disk had a comparable grain size (ASTM 11) to inner ring specimens.

\section{Failure Modes}

Typical failure initiation sites are shown in Fig. 5. Two predominant failure modes were observed. The fine grain inner ring specimens usually failed from small internal non-metallic inclusions. For the coarse grain outer specimens as well as mid and radial specimens which contained at least some coarse grain microstructure, the failures initiated at crystallographic facets which sectioned large grains.

The inclusions initiating failures were usually granulated, aluminum-rich oxide Type 2 (T2) inclusions [13, 14]. These failures initiated internally, and this difference in failure mode and location helped explain the longer lives of inner specimens compared to mid, outer, and radial locations.

The facet failure mode, associated with the coarse grain microstructures, resulted in lower fatigue lives at both $427^{\circ} \mathrm{C}$ and $704{ }^{\circ} \mathrm{C}$ than for inclusion-initiated failures of fine grained inner and bore specimens. For this apparent reason, radial specimens failed at locations corresponding to outer ring specimens, where larger grains were present to give earlier facet failures. Also, in case of the mid specimens, the crack initiation leading to failure was always located in the coarse grain section of the specimen cross section.
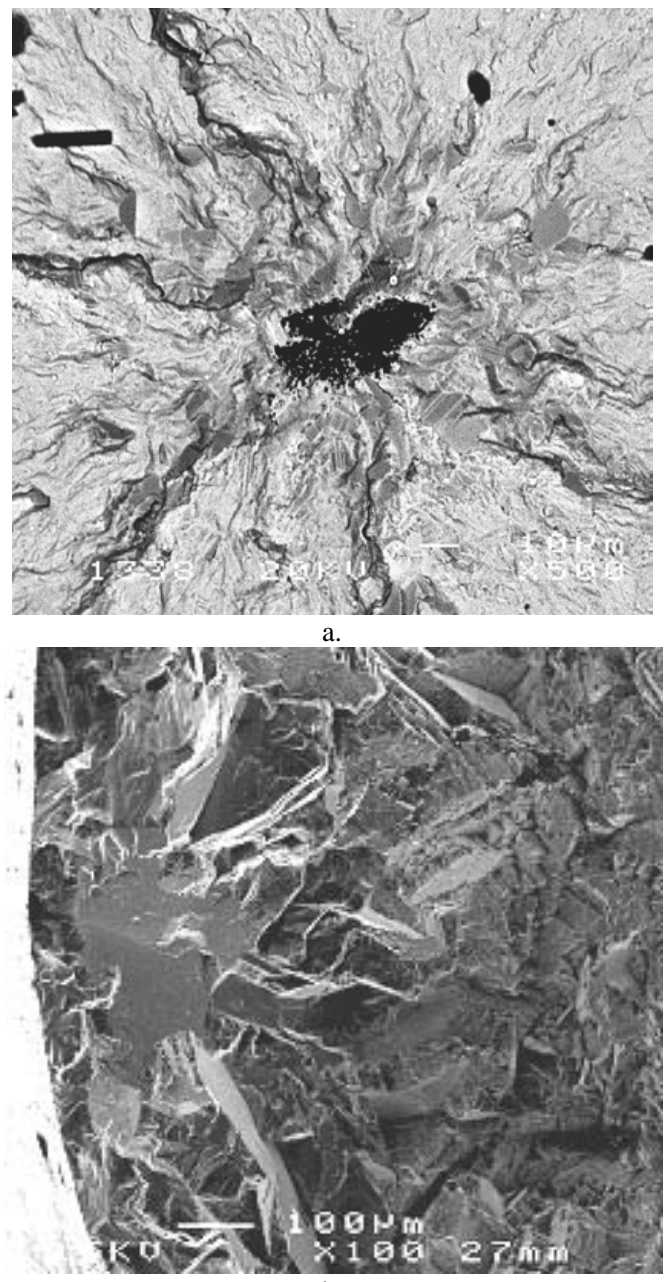

Fig. 5. Comparison of failure initiation modes in uniform gage specimens, a. inclusion failure, b. facet failure.

These facet fatigue failures usually initiated near or at the specimen surface in tests of mid, outer, and radial specimens at $427^{\circ} \mathrm{C}$. However, several of these specimens failed from internal facet locations in tests at $704{ }^{\circ} \mathrm{C}$, which resulted in longer lives than for surface initiated failures. This variation of failure location with temperature may have contributed to the lower lives observed at $427^{\circ} \mathrm{C}$ than for $704{ }^{\circ} \mathrm{C}$.

Fatigue Lives of DMHT and Uniform Grain Size Disks

Fatigue tests were previously performed at $427{ }^{\circ} \mathrm{C}$ and $704{ }^{\circ} \mathrm{C}$ in another study of LSHR [12], from a disk of exactly the same chemistry, extrusion, and size as the DMHT disk, but having a microstructure with uniform grain size. Comparison of the results from the prior and present studies could aid understanding of the mechanisms governing low cycle fatigue behavior here.

One of these prior disks had been given a conventional supersolvus heat treatment, followed by the same $815^{\circ} \mathrm{C} / 8 \mathrm{~h}$ aging heat treatment used in the DMHT disk tested here. The mean linear intercept grain size of this supersolvus disk was 
approximately $33 \mu \mathrm{m}$ with an ALA grain size of $150 \mu \mathrm{m}$, both finer than found in mid, outer, and radial DMHT specimens. The observed fatigue lives from the isothermal supersolvus heat treated disk are included for comparison to DMHT transition zone lives in Fig. 4. DMHT mid, outer, and radial specimens had significantly lower fatigue lives than those for the supersolvus disk at both $427^{\circ} \mathrm{C}$ and $704{ }^{\circ} \mathrm{C}$, at a 1-way ANOVA significance of over $95 \%$.

Several factors, including grain size, were explored to gain an understanding why fatigue lives were lower for the DMHT disk at these transition zone locations than for the uniform supersolvus disk. Tensile and creep fatigue properties of the DMHT disk rim were previously determined to be comparable to those for the supersolvus disk [9]. The disks were also shown to have similar $\gamma^{\prime}$ precipitate morphologies. However, the differences in fatigue life between the two disks could still be due in part to variations of cyclic stress range and mean stress response in fatigue tests of a given strain range. Such differences in cyclic stresses can be accounted for using a stress parameter proposed by Smith, Watson, and Topper [15]:

$$
\sigma_{\mathrm{SWT}}=\left(\sigma_{\max } \Delta \sigma / 2\right)^{0.5}
$$

This relationship accounts for differences in maximum stress as well as stress range. Fatigue lives versus $\sigma_{\mathrm{SWT}}$ are compared for these cases in Fig. 6. No consistent variations in $\sigma_{\mathrm{SWT}}$ were observed that could account for the differences in life between the DMHT and supersolvus disks. However, $\sigma_{\mathrm{SWT}}$ was usually higher at $427^{\circ} \mathrm{C}$ than for $704{ }^{\circ} \mathrm{C}$ at a given strain range, which could help explain the lower strain-life responses observed at $427^{\circ} \mathrm{C}$ for both disks.

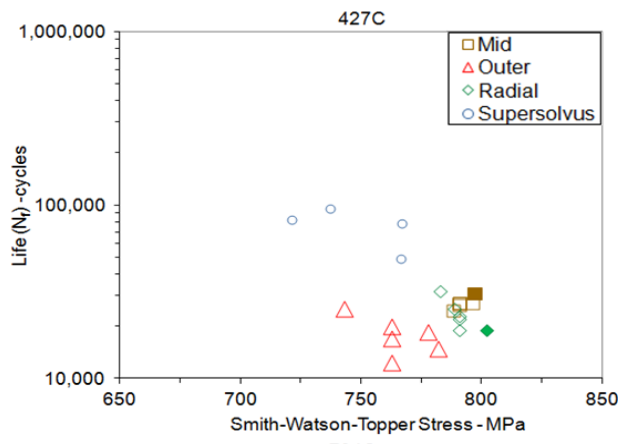

$704 \mathrm{C}$

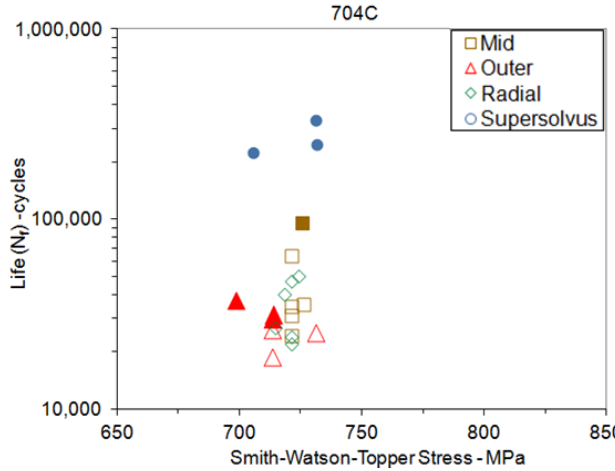

Fig. 6. Smith-Watson-Topper stress $\left(\sigma_{\mathrm{SWT}}\right)$ versus fatigue life at $427{ }^{\circ} \mathrm{C}$ and $704{ }^{\circ} \mathrm{C}$, showing no consistent correlations. Filled symbols indicate internally initiated failures, open symbols indicate surface and near-surface initiated failures.
Grain texture and the percentage of twins and low angle grain boundaries were also compared for the supersolvus and DMHT disks. Texture, twin, and low angle grain boundary content were comparable for the supersolvus and DMHT mid and outer disk locations. Therefore, differences in grain size seemed to be mainly responsible for the differences in fatigue life between the DMHT transition zone and supersolvus disk specimens.

The supersolvus specimens failed from surface facets at $427^{\circ} \mathrm{C}$, but from internal facets at $704{ }^{\circ} \mathrm{C}$, Fig. 7. The sizes of these facets appeared smaller than for DMHT specimens. For uniform gage specimens, one-way analysis of variance comparisons of $\log$ (facet area) indicated supersolvus specimens had smaller mean facet areas than mid, outer, and radial specimens at both test temperatures, at a statistical significance of over $95 \%$. The mean facet areas of mid, outer, and radial DMHT disk specimens did not differ significantly. This is consistent with the very small variation in mean fatigue lives for these three DMHT locations, as was noted earlier.
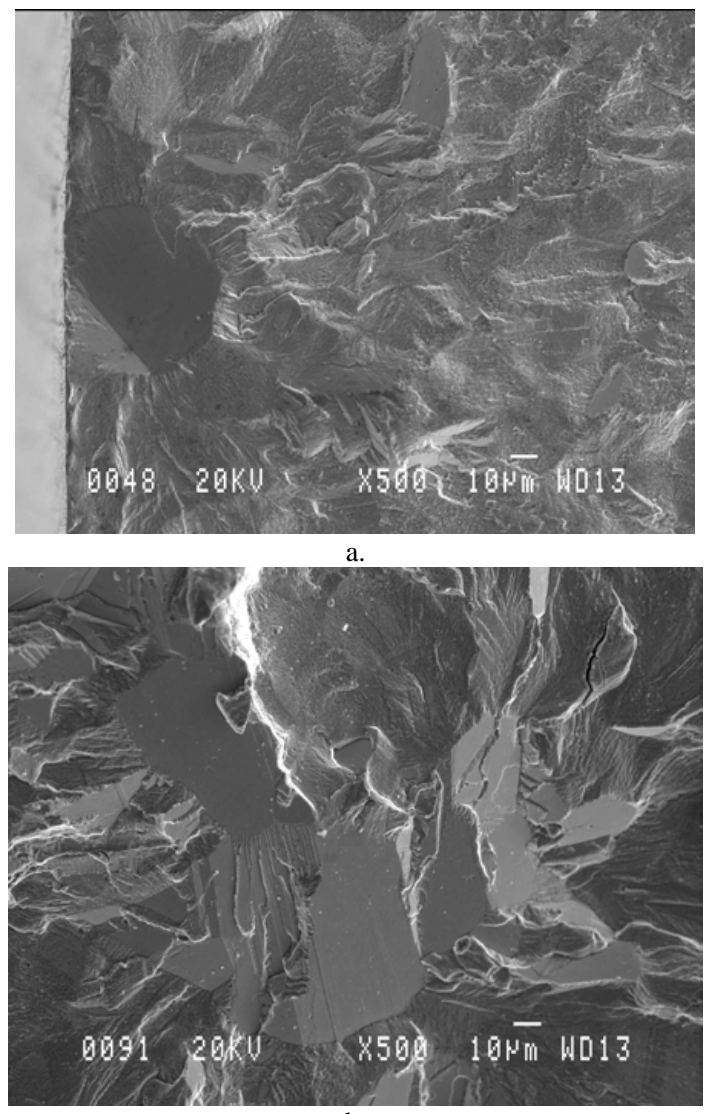

Fig. 7. Failure initiation modes for supersolvus specimens, a. surface facet at $427^{\circ} \mathrm{C}$, b. internal facet at $704^{\circ} \mathrm{C}$.

Notched Fatigue Lives in the Transition Zone

Disk rims can have varied geometrical features that act as localized stress concentration sites, including corners, blade slots, and cooling holes. The stress concentration effects of a notch were screened in tests at $704{ }^{\circ} \mathrm{C}$, using a simple circumferential 
notch with an elastic stress concentration factor $\left(\mathrm{K}_{\mathrm{t}}\right)$ of 2 on cylindrical specimens from the inner, mid, and outer locations of the DMHT disk, and from the rim of the supersolvus disk. The volume of material subjected to the net section stress in these specimens would be less than $5 \%$ that of the uniform gage specimens, and maximum axial stresses would only be concentrated near the surface of the notch root. This could minimize the potential for internal failure initiations as observed in prior tests of uniform gage specimens. The resulting lives in cyclic fatigue tests are compared in Fig. 8. Mean lives of DMHT inner, mid, and outer specimens were each separated by about $3 \mathrm{x}$ in these cyclic tests. Inner samples had higher mean life than that of mid and outer specimens at a $95 \%$ significance level, but had more scatter in life in these limited tests. Supersolvus specimens again had fatigue lives midway between inner and mid specimens, but with less scatter than inner specimens.

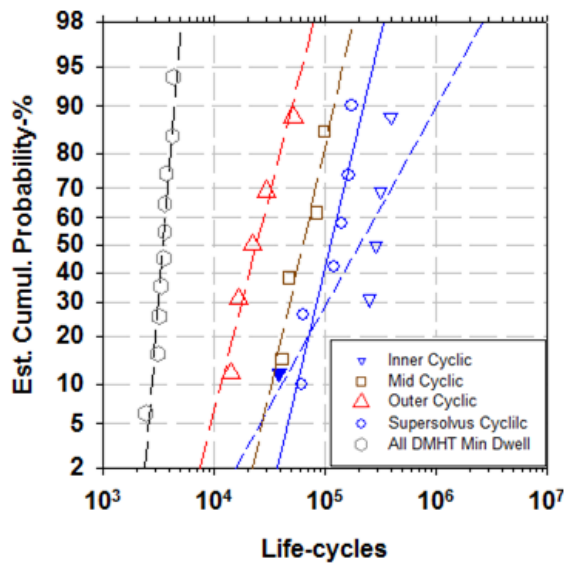

Fig. 8. Comparison of notch fatigue lives at $704{ }^{\circ} \mathrm{C}$. Filled symbols indicate internally initiated failures, open symbols indicate surface and near-surface initiated failures.

Notch Failure Modes

Typical failure initiation sites in cyclic tests of notched specimens are shown in Fig. 9. DMHT inner specimens usually failed from pores or T2 inclusions $8 \mu \mathrm{m}-30 \mu \mathrm{m}$ in diameter near or at the notch surface. However, an inner specimen having nearly $10 \mathrm{x}$ lower life than all others failed from an internal Type 2 inclusion $12 \mu \mathrm{m}$ in diameter, at a minimum depth of $29 \mu \mathrm{m}$. This curious response could be related to complex interactions between the concentration of stress near the surface of the notch, surface compressive residual stresses from notch machining process [14], and the tendencies for initiation of cracks at such small defects. Certainly, it helped illustrate that while such fine grain microstructures of inner specimens can give longer mean fatigue lives than for coarse grains, they can be more sensitive to such small defects, to give more scatter in life at highly stressed surfaces $[13,14]$. DMHT mid and outer specimens as well as supersolvus specimens usually failed from surface or near-surface facets.
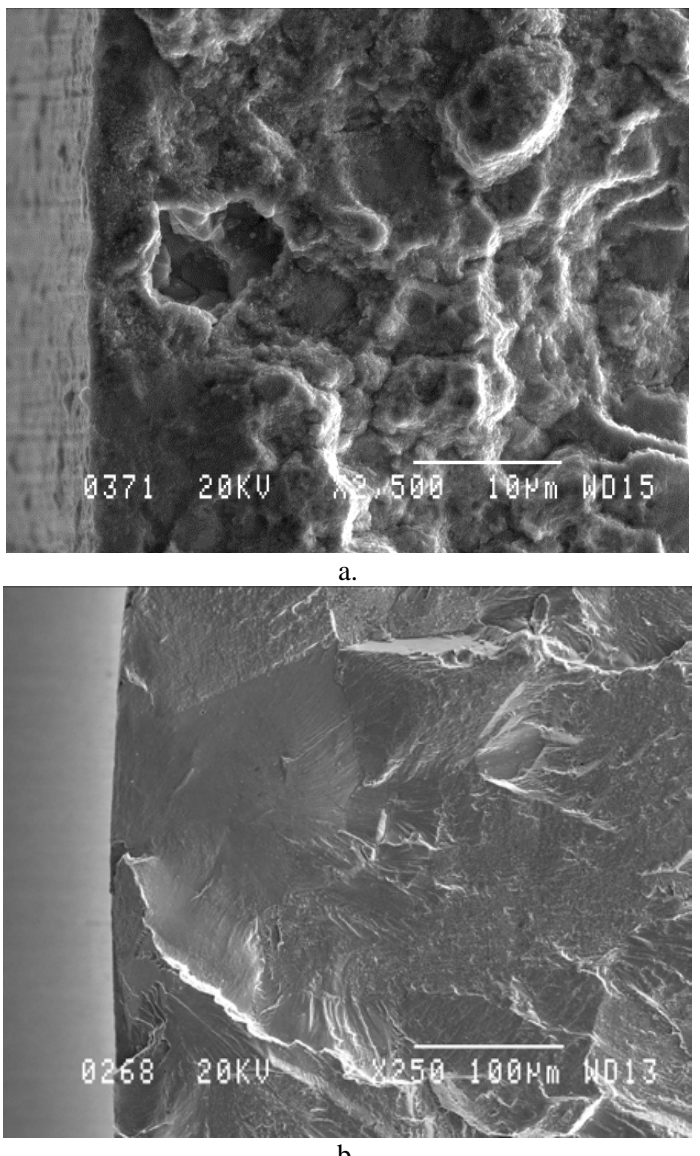

Fig. 9. Notch fatigue failure initiation modes, a. pore, b. facet.

The relationships between the size of the facets initiating failure and fatigue life for DMHT and supersolvus, uniform gage and notch fatigue specimens are shown in Fig. 10. For tests at both $427{ }^{\circ} \mathrm{C}$ and $704{ }^{\circ} \mathrm{C}$, uniform gage fatigue specimens removed from the supersolvus disk had smaller facet sizes than those for specimens excised from the DMHT disk. The size of the facets was related to the corresponding fatigue lives. Decreasing facet size correlated with increasing fatigue life for all facet failures in uniform gage specimens at both test temperatures. The correlation as indicated by the coefficient of determination was higher at $427^{\circ} \mathrm{C}$ than for $704{ }^{\circ} \mathrm{C}$. This appeared related in part to the locations of facet failures. Most facet failures initiated at the surface for tests at $427^{\circ} \mathrm{C}$. However, several specimens failed from internal grain facets at $704{ }^{\circ} \mathrm{C}$, producing longer lives than for surface initiated failures. Such variations in life based on failure location have been observed in other disk superalloys [13, 16]. Facet sizes for uniform gage specimens did not significantly vary between the two testing temperatures.

Facet sizes for notched specimens were smaller than for uniform gage specimens, and did not consistently vary with location. Oneway ANOVA evaluations indicated facets causing failure in notched specimens DMHT and supersolvus disks were not significantly different, and did not correlate with fatigue life. 
Grouped together, facets of notched gage specimens were significantly smaller than for uniform gage specimens.
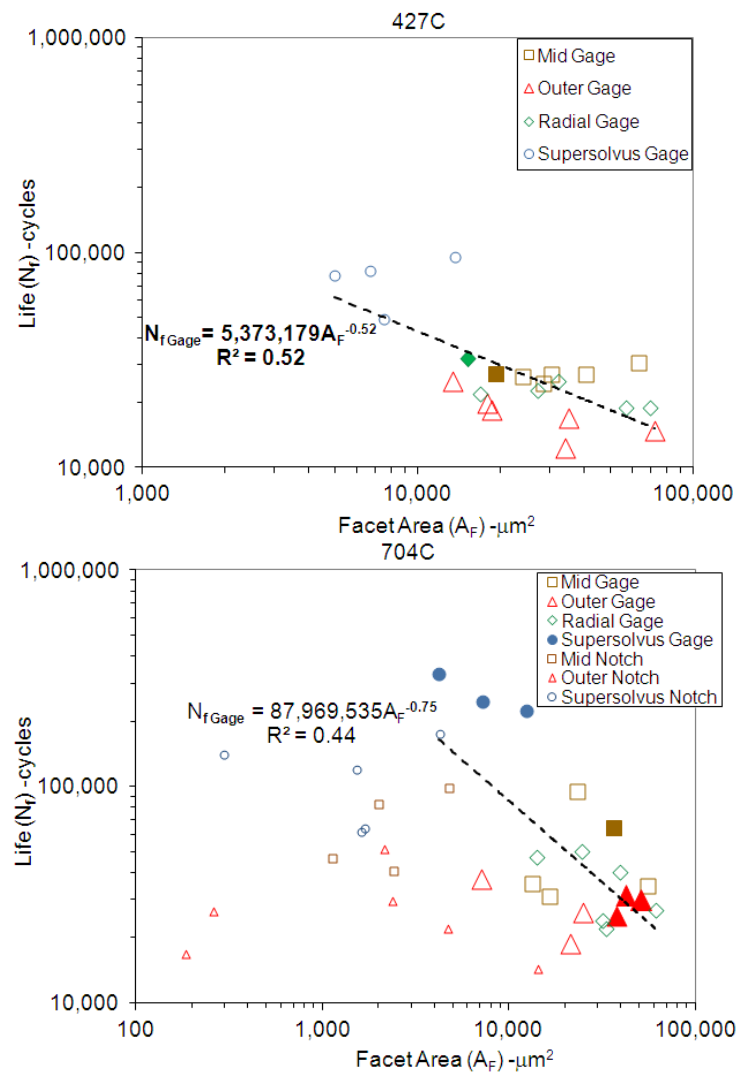

Fig. 10. Fatigue life versus facet areas at $427^{\circ} \mathrm{C}$ and $704{ }^{\circ} \mathrm{C}$. Regression lines indicate correlation of facet area with uniform gage lives only. Filled symbols indicate internally initiated failures, open symbols indicate surface and near-surface initiated failures.

The grain facet sizes could be compared to the grain size distributions of the samples. Grain and facet size distributions are compared for DMHT mid, outer, and radial locations and for the supersolvus disk in Fig. 11. The grain areas of the supersolvus disk were significantly smaller than those of mid and outer ring specimens of the DMHT disk, due to the different heat treatment temperature-time paths of these two disks. Facets causing failures in uniform gage specimens were in the upper $30 \%$ of grain areas measured for each location. Such response has been observed in other disk superalloys $[11,12]$. However, grain facets causing failures in notched gage specimens were of typical size, and not relatively large grains within each grain size population.

The relatively large size of a grain within a grain size distribution appeared to be a first order determinant for facet failures in uniform gage specimens for the current test conditions. ALA grain size as determined according to ASTM E930 could be used as a simple, well established measurement for bounding fatigue life in such conditions [17]. ALA grain size could then correlate reasonably well with fatigue life at each temperature, and could be used as a practical predictor for upper bounds of facet grain size [11]. Here, it should be understood that facet size will approach but often be smaller than actual ALA size for each disk and specimen location.

It would be expected that crystallographic orientation of grains would also be important, in order to allow high resolved shear stress to cause facet failures on operative slip planes. This was proven the case for high cycle fatigue failures of Rene' 88DT in [9]. The resolved shear stress within grains could also be affected by the local applied stress state, and by resolved shear stresses of surrounding grains, including their magnitudes and orientations. Such stress issues could largely explain the results for notched specimens. These specimens had a far smaller volume of material at near maximum applied stress, and also a multi-axial stress state near the notch tip. Here, failures were all at grains of more typical size in the population located at the location of maximum stress concentration. The grains causing failures could have been more favorably oriented for maximized shear stresses on the facet planes.

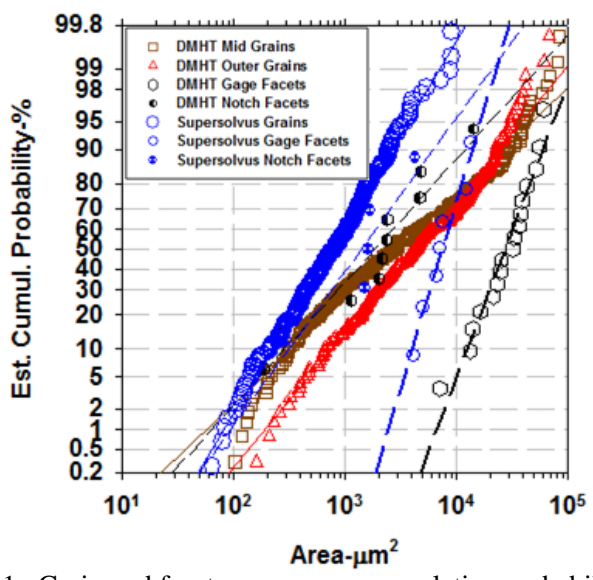

Fig. 11. Grain and facet areas versus cumulative probability.

It appears a properly calibrated correlation of facet size versus fatigue life at relevant conditions could be analytically combined with the measured distribution of grain sizes at a disk location, to generate probabilistic predictions of cyclic life there. But present results indicate such a calibration would have to account for the volume and grain population under applied stress, and also the effects of multi-axial stress states at disk features and notches. This could require specimens of purposefully varied stressed volumes, and varied notch geometries.

Effects of Dwells on Fatigue Failures in the Transition Zone Mean fatigue life in the transition zone decreased with increasing grain size in a systematic manner for these conventional triangular control waveforms. However, the cyclic waveforms and frequencies used in these tests were chosen for convenience, and were far faster than that typically expected in the major cycles of commercial aerospace turbine engine applications. Here, a flight can have dwell periods of several minutes near maximum power, stress, and temperature. A simple dwell fatigue test was performed at $704{ }^{\circ} \mathrm{C}$ to assess this effect, on notched specimens from the inner, mid, and outer locations of the transition zone.

Uniform gage and notched fatigue specimens can experience excessive relaxation of tensile stresses in uniform gage specimens 
during dwells at maximum applied strain [16], and in notch specimens during dwells at maximum applied stress [18]. Therefore, the present dwell tests were performed using a cycle with a triangular waveform segment at $0.5 \mathrm{~Hz}$ to first vary applied stress, followed by a dwell of $90 \mathrm{~s}$ at minimum applied stress. Models simulating the evolution of tensile stresses in notches [18, 19] have shown maximum and minimum stresses should be stable in this cycle, and remain comparable to those of the conventional cyclic tests as used here. This dwell cycle has been shown to limit fatigue life in several PM superalloys, combining fatigue and environmental damage while preserving similar tensile stresses as the cyclic tests with no dwells $[18,19]$. The resulting lives are included for comparison in Fig. 8. This dwell cycle gave comparable lives for inner, mid, and outer specimens, in spite of their varying grain microstructures. Dwell cycle life was significantly lower than for all cyclic tests run at $704{ }^{\circ} \mathrm{C}$ using the same applied stress levels.

The associated failure initiation mode in these dwell tests is shown in Fig. 12. Inner, mid, and outer transition zone specimens all failed from transgranular cracks initiating from the oxidized surfaces. The oxidized features initiating these cracks in a very similar disk superalloy ME3 are considered in more detail elsewhere [18]. This failure mode could ultimately limit fatigue life in the transition zone for many aerospace turbine disk applications, if exposed to such stress cycles.

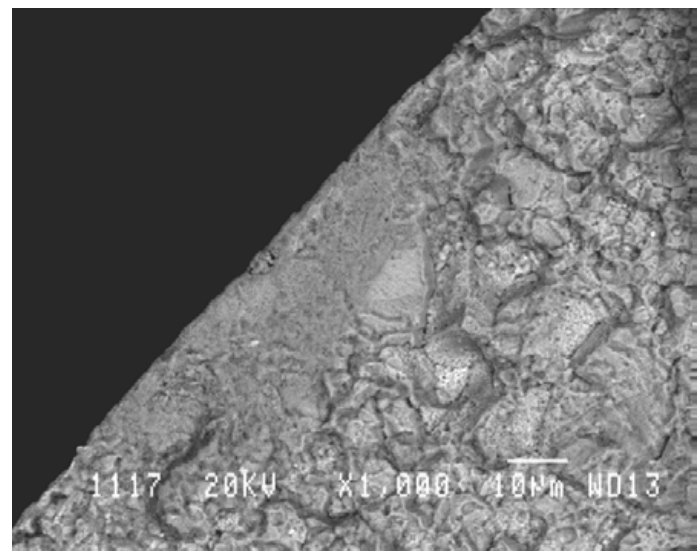

a.

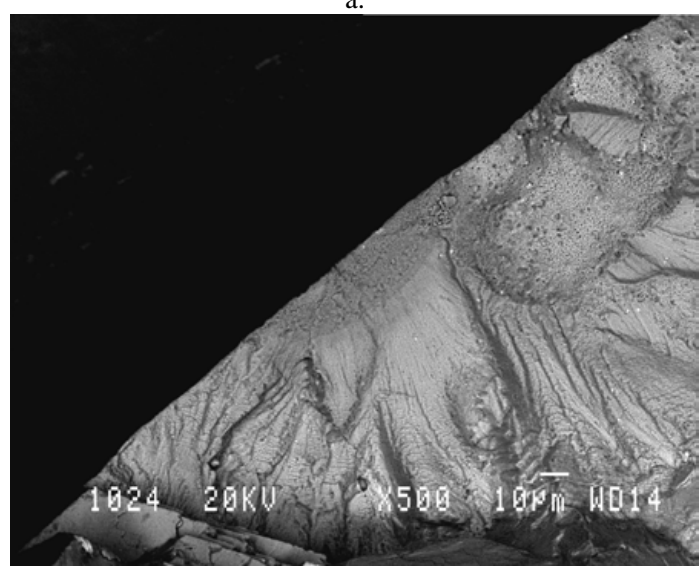

b.

Fig. 12. Failure initiation mode in dwell tests of notched specimens at $704{ }^{\circ} \mathrm{C}$, a. inner specimen, b. outer specimen.

Potential Future Work

Additional work could be performed to improve the understanding and balance of microstructure-fatigue life relationships in the transition zone of DMHT disks. Longitudinal sectioning after testing of uniform gage and notched specimens at varied temperature and stress levels could be used to uncover multiple cracked grains (facets). This could allow an understanding of the applied stress and stress state, grain size, crystallographic orientation, and surrounding grain constraints necessary for fatigue crack initiation at facets. Tests varying dwell cycle, temperature, and applied stress could also help in understanding how fatigue, environment, and stress relaxation interact to encourage surface cracking. Predictive models could then be developed for life predictions.

Such knowledge could also be applied to help guide enhancement of transition zone and rim microstructures for improved fatigue properties. Varied disk forging conditions have been found to significantly influence grain size response in powder metallurgy disk superalloys during subsequent heat treatments [20]. Therefore, varied forging conditions could be used to help tailor grain size and fatigue properties in the transition zone and rim. Yet, it is not clear that these modifications would improve resistance to surface cracking observed in the dwell fatigue cycles. 
Surface modifications might be needed here, including processes that locally vary microstructure, introduce sustained compressive residual stresses, or apply environment-resistant coatings, in order to improve resistance to this fatigue crack initiation mode.

Any resulting improvements in fatigue crack initiation properties would need to be balanced with many other mechanical properties of importance for mechanical design of location specific microstructure disks. Depending on the location and service conditions of a transition zone, these could include cyclic fatigue crack growth, dwell fatigue crack growth, burst strength, and monotonic creep resistance, at both uniform and notched locations.

\section{Summary and Conclusions}

The fatigue life, failure modes and microstructure of the transition zone of a DMHT disk were characterized using LCF tests, quantitative fractography, and metallography. Specimens located at an inner ring just within the transition zone had fatigue lives comparable to bore specimens, and were much longer than specimens located at mid and outer rings of the transition zone. The bore and inner ring specimens had a fine grain size and failed mostly from internal inclusions. The mid and radius specimens contained both coarse and fine grain size microstructures, but always failed from coarse grain facets. The coarse grain outer ring specimens also failed from large grain crystallographic facets. The grain facet failure initiations resulted in substantially lower mean fatigue lives than for inclusion failures.

The grain facets initiating failure were generally larger than the mean grain size, extending to near ALA grain size. The lives of specimens located mid way in the transition zone, with near bimodal grain size, appeared to still be limited by these large grains, with no additional complications due to wider grain size variations. A conventional supersolvus heat treated disk had about $5 x$ longer fatigue life than mid and outer DMHT specimens, which could be explained by consideration of the sizes of their largest grains.

Notched specimens failed from cracks initiating near or at the notch surface, usually at the same failure sites as for uniform gage specimens. However, local concentrated stress state and resolved shear stress issues were dominant here. These specimens had a far smaller volume of material at near maximum applied stress, and also a multi-axial stress state near the notch tip. This encouraged failures at the location of maximum stress concentration, at favorably oriented grains of more typical size in the population.

It can be concluded from this work that the cyclic fatigue failure response of the transition zone region behaves in a predictable manner for this DMHT disk, varying with maximum grain size, stressed volume and stress state for the current material and test conditions. Simple screening of grain size distributions may be useful to initially estimate mean cyclic fatigue life in such location specific microstructure disks. Subsequently, a carefully calibrated correlation of facet size versus fatigue life could be analytically combined with measured distributions of grain sizes versus disk location and stress state, to generate probabilistic life predictions. Thus, careful control, measurement, and then prediction of grain size distribution as a function of location will be important for accurate cyclic fatigue life prediction of DMHT disks having location specific microstructures and mechanical properties.

However, cyclic fatigue at notches would stress only small volumes of material, and require consideration of varied stressed volumes and associated numbers of grains in grain size - fatigue life probability considerations. Furthermore, dwell fatigue cycles promoting fatigue - environment damage at notches can be less sensitive to grain size variations in the transition zone, and not responsive to tailored grain size approaches. Several processing avenues may offer further refinements of surface composition, microstructure, and residual stresses for enhancing fatigue life here. However, other mechanical properties need to be considered for such refinements and optimizations.

\section{Acknowledgements}

The authors wish to acknowledge the support of the NASA Aviation Safety and Subsonic Fixed Wing programs. Disk forging was performed at PCC Wyman-Gordon Forgings under the direction of Ian Dempster. Disk heat treatments were performed at Ladish Forgings, Inc. under the direction of Joe Lemsky, and David Furrer, now at Pratt \&Whitney Aircraft.

\section{References}

1. C. T. Sims, N. S. Stoloff, W. C. Hagel, Superalloys II, John Wiley \& Sons, New York, NY, 1987, p. 477.

2. R. C. Reed, The Superalloys, Cambridge University Press, Cambridge, U.K., 2006, p. 242

3. T. E. Volin, J. S. Benjamin, J. M. Larson, R. L. Cairns, “Thermoplastic Prealloyed Powder”, U.S. Patent 3,930,841, U. S. Patent and Trademark Office, Washington, D.C., January, 1976.

4. J. L. Bartos, P. S. Mathur, "Development of Hot Isostatically Pressed (as-HIP) Powder Metallurgy Rene' 95 Turbine Hardware", Superalloys: Metallurgy and Manufacture, ed. B. H. Kear, D. R. Muzyka, J. K. Tien, S. T. Wlodek, Claitor's Publishing Div., Baton Rouge, LA, 1976, pp. 495-508.

5. G. F. Mathey, Method of Making Superalloy Turbine Disks Having Graded Coarse and Fine Grains, U.S. Patent 5,312,497, U. S. Patent and Trademark Office, Washington, D.C., May, 1994.

6. S. Ganesh, R. G. Tolbert, Differentially Heat Treated Article, and Apparatus and Process for the Manufacture Thereof , U.S. Patent 5,527,020, U. S. Patent and Trademark Office, Washington, D.C., June, 1996.

7. J. Gayda, T. P. Gabb, P. T. Kantzos, "The Effect of Dual Microstructure Heat Treatment on an Advanced Nickel Base Disk Alloy", Superalloys 2004, ed. K. A. Green, T. M. Pollock, H. Harada, T. E. Howson, R. C. Reed, J. J. Schirra, S. Walston, The Minerals, Metals \& Materials Society (TMS), Warrendale, PA, 2004, pp. 323-329.

8. R. J. Mitchell, J. A. Lemsky, R. Ramanathan, H. Y. Li, K. M. Perkins, L. D. Connor, "Process Development \& Microstructure \& Mechanical Property Evaluation of a Dual Microstructure Heat Treated Advanced Nickel Disc Alloy", Superalloys 2008, ed. R. C. Reed, K. A. Green, P. Caron, T. P. Gabb, M. G. Fahrmann, E. S. Huron, S. A. Woodard, TMS, Warrendale, PA, 2008, pp. 347-356.

9. J. Miao, T. M. Pollock, J. Wayne Jones, "Crystallographic Fatigue Crack Initiation in Nickel-based Superalloy Rene' 88DT at Elevated Temperature”, Acta Materialia 57 (2009) 5964-5974. 
10. T. P. Gabb, J. Telesman, P. T. Kantzos, A. Garg, "Effects of Temperature on Failure Modes for a Nickel-base Disk Superalloy”, J. Failure Analysis and Prevention 7 (2007) 5665.

11. T. P. Gabb, P. T. Kantzos, J. Telesman, J. Gayda, C. K. Sudbrack, B. Palsa, "Fatigue Resistance of the Grain Size Transition Zone in a Dual Microstructure Superalloy Disk", Int. J. Fatigue, 33 (2011) 414-426.

12. T. P. Gabb, J. Gayda, J. Telesman, P. T. Kantzos, “Thermal and Mechanical Property Characterization of the Advanced Disk Alloy LSHR”, NASA/TM-2005-213645, Washington, D.C., 2005.

13. D. R. Chang, D. D. Krueger, R. A. Sprague, "Superalloy Powder Processing, Properties, and Turbine Disk Applications", Superalloys 1984, ed. M. Gell, C. S. Kortovich, R. H. Bricknell, W. B. Kent, J. F. Radavich, TMS, Warrendale, PA, 1984, pp. 245-252.

14. R. L. Barrie, T. P. Gabb, J. Telesman, P. T. Kantzos, A. Prescenzi, T. Biles, P. J. Bonacuse, "Effectiveness of Shot Peening in Suppressing Fatigue Cracking at Non-metallic Inclusions in Udimet 720", NASA/TM-2005-213577, Washington, D.C., 2005.

15. K. N. Smith, P. Watson, T. H. Topper, “A Stress-Strain Function for the Fatigue of Metals”, Journal of Metals, 5 (1970) 767-778.

16. T. P. Gabb, J. Telesman, P. T. Kantzos, J. W. Smith, "Effects of High Temperature Exposures on Fatigue Life of Disk Superalloys", Superalloys 2004, ed. K. A. Green, H. Harada, T. E. Howson, T. M. Pollock, R. C. Reed, J. J. Schirra, S. Walston, TMS, Warrendale, PA, 2004, pp. 269-274.

17. M. L. Brogdon, A. H, Rosenberger, "Evaluation of the Influence of Grain Structure on the Fatigue Variability of Waspaloy”, Superalloys 2008, ed. R. C. Reed, K. A. Green, P. Caron, T. P. Gabb, M. G. Fahrmann, E. S. Huron, S. A. Woodard, TMS, Warrendale, PA, 2008, pp. 583-588.

18. J. Telesman, T. P. Gabb, Y. Yamada, L. J. Ghosn, D. Hornbach, N. Jayaraman, "Dwell Notch Low Cycle Fatigue Behavior in Powder Metallurgy Nickel Disk Alloy", Superalloys 2012, ed. E. H. Huron, M. Hardy, M. Mills, R. Montero, P. Portella, J. Telesman, R. Reed, TMS, 2012.

19. M. R. Bache, J. P. Jones, G. L. Drew, M. C. Hardy, N. Fox, "Environment and Time Dependent Effects on the Fatigue Response of an Advanced Nickel Base Superalloy”, Int. J. Fatigue, 31 (2009) 1719-1723.

20. E. Huron, S. Srivatsa, E. Raymond, "Control of Grain Size Via Forging Strain Rate Limits for R'88DT”, Superalloys $\underline{2000}$, ed. T. M. Pollock, R. D. Kissinger, R. R. Bowman, K. A. Green, M. McLean, S. Olson, J. J. Schirra, TMS, Warrendale, PA, 2000, pp. 49-58. 